\title{
Extraction of eco-friendly natural dyes from mango leaves and their application on silk fabric
}

\author{
Mohammad Gias Uddin
}

\begin{abstract}
The aim of the study was to evaluate the performance of dyes extracted from mango leaves in silk dyeing. Extraction medium was optimized by extracting dyes from fixed quantity of crushed leaves under $\mathrm{pH}$ values from 3 to 12 . The maximum relative color strength of the extracted dye liquor was found to be at $\mathrm{pH} 10$. The optimum dye extraction conditions i.e., the temperature, time, and material-to-liquor ratio were found to be $98{ }^{\circ} \mathrm{C}, 60$ min, and 1:10, respectively. Dyeing was carried out with the optimized dye extract on mordanted and unmordanted silk fabrics. The dyed materials were evaluated by measuring the color yield and fastness properties. It was concluded that the color values were found to be influenced by the addition of mordants, consequently different fashion hues were obtained from the same dye extract using different mordants. It can also be said that mango leaves have good potentiality for dyeing of silk fabric.
\end{abstract}

\section{Background}

Textile dyeing industry at present uses excessive amount of synthetic dyes to meet the required coloration of global consumption of textiles due to cheaper prices, wider ranges of bright shades, and considerably improved fastness properties in comparison to natural dyes (El-Nagar et al. 2005; Iqbal et al. 2008). But the production of synthetic dyes is dependent on petrochemical source, and some of these dyes contain carcinogenic amines (Hunger 2003). The application of such dyes causes serious health hazards and influences negatively the eco-balance of nature (Bruna and Maria 2013; Goodarzian and Ekrami 2010; Jothi 2008). Moreover, many countries already imposed stringent environment standards over these dyes. For instance, Germany has banned the azo dyes (Almahy et al. 2013). In this situation, a higher demand is put towards the greener alternatives or agricultural residues (Ammayappan et al. 2014). As a result, natural dyes are among the promising options for developing a greener textile dyeing process and such interest is reflected to the increased number of recent publications. Plant leaves are potential sources of natural dyes because of their easy availability and abundant nature.

Correspondence: giasdtt@gmail.com

Department of Textile Engineering, Faculty of Engineering, Ahsanullah University of Science and Technology, Dhaka 1208, Bangladesh
Silk has been known as the "queen of fibers" since its discovery. Clothes made from silk are luxurious and have many excellent qualities including the material's luster, light weight, superior mechanical performance, fine and smooth texture, excellent moisture transportation, and excellent draping quality (Cai et al. 2001). Mango bark has been reported to be used on silk and cotton materials as a source of natural dyes, and a wide range of colors have been produced using different mordants (Bains et al. 2003; Win and Swe 2008). On the other hand, the use of acid activated mango leaf powder (MLP) has been reported in another study for the removal of the Rhodamine B (RB) dye from aqueous solution (Khan et al. 2011). However, apart from this application of mango leaves, different leaves such as peach, poinsettia, acalypha, and parthenium leaves have also been reported to extract colors which were used in dyeing of silk materials (Mahajan et al. 2005; Rawat et al. 2006; Saravanan et al. 2013; Suneeta and Mahale 2002) while mango leaves have been reported to be used in batik painting technique on silk fabric in comparison with other four natural dyes (Klaichoi and Padungtos 2010). There is scope to extract color from mango leaves for the use in dyeing of silk fabric in order to get different fashion hues. The aim of the research was to evaluate the performance of dyes extracted from mango leaves in silk dyeing. The specific objectives were to analyze the aqueous extraction process of the dyes, to explore the possibilities of producing fashionable hues from the dyes using different mordants, to compare between unmordanted and mordanted dyed 


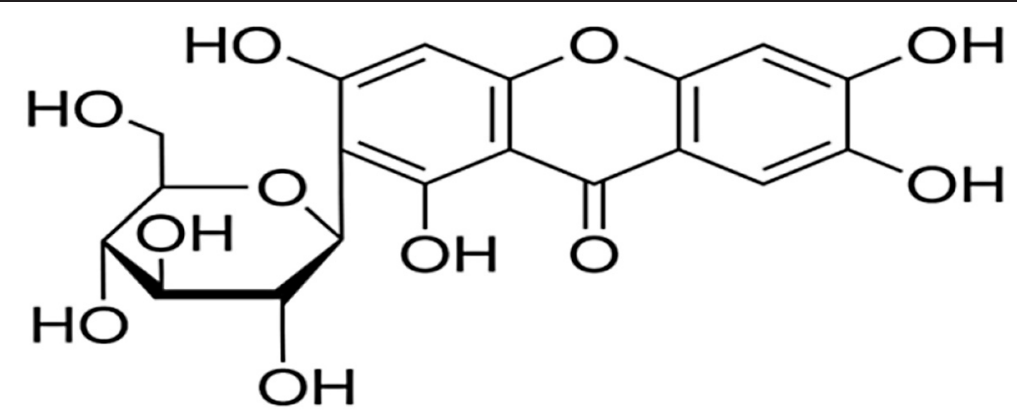

Fig. 1 Chemical structure of mangiferin

fabrics, to analyze the color values, and to assess the color fastness properties of dyed fabric.

\section{Methods}

\section{Materials}

Mango leaves used for the extraction purpose was collected from Roads \& Highways Department, Dhaka, Bangladesh. Mangiferin as shown in Fig. 1 (1,3,6,7-tetrahydroxyxanthone-C-2- $\beta$-D-glucoside) was the chemical responsible (Luo et al. 2012) for providing color from mango leaves. Plain weave (1/1) raw silk fabric ( $22 \mathrm{~g} / \mathrm{m}^{2}$ fabric) purchased from Sopura Silk Limited, Dhaka, was used for this study.

\section{Extraction}

The leaves were washed thoroughly with water to remove dirt. They were dried under direct sunlight and grinded into very small units with the help of a grinding machine. The wastages are removed using a fine strainer, and finally, weight was taken. After drying, crushing, and removing wastages, the weight of 1 kilogram leaves was found to be 318 gram. Raw, dried, and crushed leaves are shown in Fig. 2.

The color component was extracted from the leaves in aqueous extraction process. Extraction was carried out with fixed quantity of crushed leaves (10 gram) under ten different $\mathrm{pH}$ values from $\mathrm{pH} 3$ to 12 with a liquor ratio of 1:10 (Weight of crushed leaves in gram; amount of water in milliliter) at $98{ }^{\circ} \mathrm{C}$ for $60 \mathrm{~min}$ to optimize extraction medium. In each process of extraction, the mixture was cooled down and finally the dye extracts were filtered with fine filter paper three times to ensure clear dye solution.

The dye extracts obtained at different $\mathrm{pH}$ values were used for obtaining standard calibration curves through their absorbance values found using a dual beam reflectance spectrophotometer. The dilution of the extracts was carried out for the linear dependence on the concentration-absorbance relation at an absorbance peak $\left(\lambda_{\max }\right)$. The absorbance values of extracted dye liquors under alkaline $(\mathrm{pH} 8-12)$ and acidic $(\mathrm{pH} 3-6)$ conditions were considered as batches, and relative color strength values of these batch solutions were measured from the spectrophotometer by comparing with the absorbance value of extracted dye liquor under neutral condition ( $\mathrm{pH} 7$ ) which was considered as standard.

Again, the dye extract which gave the maximum color strength was utilized to optimize the extraction levels of temperature, time, and material-to-liquor ratio. An orthogonal design of experiments was undertaken for this purpose.

\section{Degumming}

Raw silk fabric was degummed in an aqueous solution containing soap $(15 \mathrm{~g} / \mathrm{L})$, sequestering agent $(1 \mathrm{~g} / \mathrm{L})$, and wetting agent $(1 \mathrm{~g} / \mathrm{L})$ maintaining the bath at $\mathrm{pH}$ 9. The

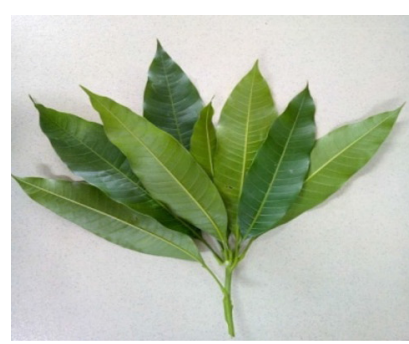

a) Raw leaves

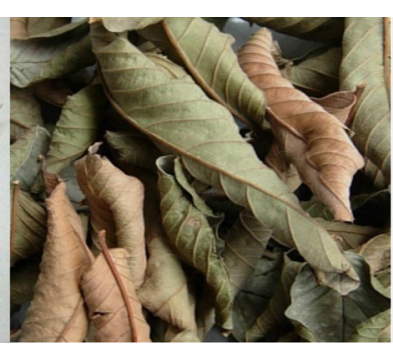

b) Dried leaves

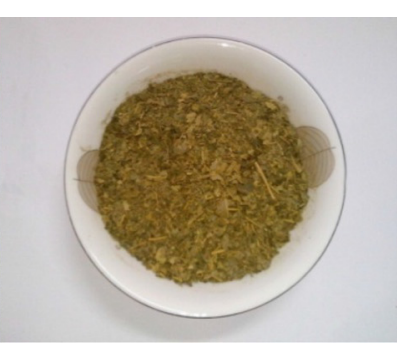

c) Crushed leaves

Fig. 2 (a) Raw, (b) dried, and (c) crushed mango leaves 
Table 1 Relative color strength of extracted dye liquors at pH 3

\begin{tabular}{ll} 
to12 & Color strength values \\
\hline 3 & 95 \\
4 & 88.6 \\
5 & 88.9 \\
6 & 95.7 \\
7 & 100 \\
8 & 103.3 \\
9 & 105 \\
10 & 108.5 \\
11 & 102.1 \\
12 & 93.3 \\
\hline
\end{tabular}

material-to-liquor ratio during the treatment was maintained at 1:50. The temperature was gradually raised to $80{ }^{\circ} \mathrm{C}$ and run for $60 \mathrm{~min}$. The degummed fabric was washed with $2 \mathrm{~g} / \mathrm{L}$ detergent at $65{ }^{\circ} \mathrm{C}$ for $10 \mathrm{~min}$.

\section{Bleaching}

The degummed fabric was bleached by treating with $35 \%$ hydrogen peroxide $(3 \mathrm{~mL} / \mathrm{L})$, sequestering agent $(1 \mathrm{~g} / \mathrm{L})$, wetting agent $(1 \mathrm{~g} / \mathrm{L})$, and trisodium phosphate $(2 \mathrm{~g} / \mathrm{L})$, maintaining a material-to-liquor ratio of 1:50 at $\mathrm{pH} 9$ and temperature $60{ }^{\circ} \mathrm{C}$ for $60 \mathrm{~min}$ followed by washing with $2 \mathrm{~g} / \mathrm{L}$ detergent at $65{ }^{\circ} \mathrm{C}$ for $10 \mathrm{~min}$. CIE whiteness index of the bleached fabric was found to be 63.26 .

\section{Mordanting}

Pre-mordanting was carried out on silk fabric using $5 \%$ (on fabric weight) of ferrous sulfate, alum (potassium aluminum sulfate), and tin (stannous chloride) mordants individually and using four different combinations of mordants such as ferrous sulfate-alum $(2.5+2.5 \%)$, ferrous sulfate-alum-tin $(2+2+1 \%)$, alum-tin $(2.5+$ $2.5 \%)$, and alum-tin-tannic acid $(2+2+1 \%)$ at $60{ }^{\circ} \mathrm{C}$ for 60 min keeping a material-to-liquor ratio of 1:30. Again, cream of tartar (CT) was used as a mordant assistant (Mortazavi et al. 2012) with stannous chloride, written as tin-CT.

\section{Dyeing}

Dyeing was carried out IR sample dyeing machine with the optimized dye extract as per standard parameters recommended for silk fabric, reported in Clariant manual, i.e., at $80{ }^{\circ} \mathrm{C}$ for $60 \mathrm{~min}$ under $\mathrm{pH} \mathrm{5}$, keeping a material-to-liquor ratio of 1:50. Opticid PSD (1.5 g/L) was used as a buffering agent in the extracted dye liquor.

\section{Color yield of dyed fabrics}

Dyed samples were analyzed by measuring the reflectance curve between 350 and $750 \mathrm{~nm}$ with the spectrophotometer with illuminant $\mathrm{D}_{65}$ at $10^{\circ}$ observer. The minimum of the curve $\left(R_{\min }\right)$ was used to determine the ratio of light absorption $(K)$ and scatter $(S)$ via the Kubelka-Munk function (Mcdonald 1997).

$$
\left(\frac{K}{S}\right)_{\text {Dyed }}=\frac{\left(1-R_{\min }\right)^{2}}{2 R_{\min }} .
$$

\section{Color coordinates of dyed fabrics}

The color coordinates of the dyed samples were determined based on the CIELab system via the spectrophotometer. In addition, $\triangle \mathrm{E}_{\mathrm{CMC}}$ value was determined to show the color difference between mordanted and unmordanted samples.

\section{Color fastness}

Washing and light fastness tests were carried out in ISO 105 C02 and ISO 105 B02 method, respectively.

\section{Results and discussion}

\section{Color strength of extracted dye liquors}

Optimum $\mathrm{pH}$ was selected based on the relative color strength value of the extracted dye liquor at which maximum color was extracted. Changes in color strength were found due to changes in $\mathrm{pH}$ as shown in Table 1.

It can be seen from the extraction results that the extracted solution showed maximum color strength at $\mathrm{pH} 10$ which was 108.5. It was also found that from the neutral condition $(\mathrm{pH} 7)$, relative color strength values gradually decreased up to $\mathrm{pH} 4$ and then increased at $\mathrm{pH}$ 3. The reason of extracting more coloring

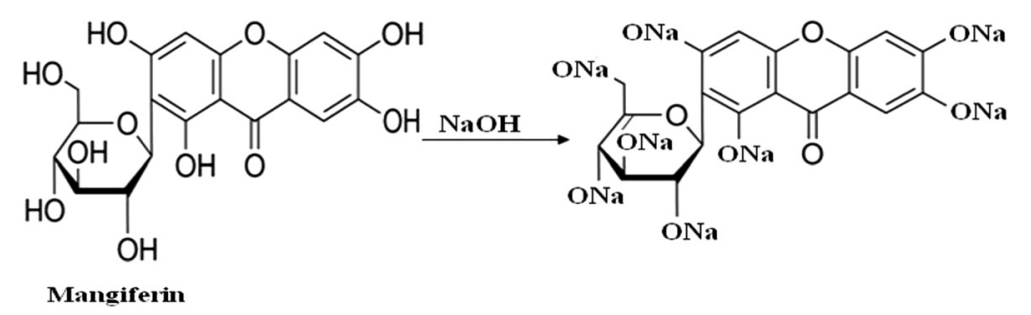

Fig. 3 Reaction of mangiferin with caustic soda 
component in alkaline medium was due to the presence of acidic phenolic groups in mangiferin which reacted with alkali and formed more soluble salts in water as shown in Fig. 3. The solubility of the coloring component was increased due to the increased ionization of hydroxyl (phenoxide) groups in alkaline medium (Ali 2007).

Again, increasing the $\mathrm{pH}$ from neutral condition improved the color strength of the extracted dye liquors up to a certain point. A further increase in alkaline $\mathrm{pH}$ resulted in decrease in the color strength of the extract. This decline in color strength was due to the high reactivity of mangiferin in concentrated alkaline medium (Spyroudis 2000).

Furthermore, the cell wall of leaves is composed of cellulosic material which gains anionic charge under alkaline medium. Because of these anionic repulsive forces among the cell walls, they lose their strength and ruptured easily (Ali 2007). In addition, as the observed leaf dyes have polyphenolic chromophoric structure, hence better extractions were observed using aqueous method (Sivakumar et al. 2009a, b).

\section{Study of pH stability of dye extracts}

It was noticeable during extraction that $\mathrm{pH}$ of the extraction bath changed gradually with time. Table 2 shows the $\mathrm{pH}$ variation after filtration and with time elapsed.

$\mathrm{pH}$ was found to be decreased in all the extraction baths from $\mathrm{pH} 3$ to 12 . This was due to the release of acidic color components from the leaves during extraction. From the neutral $\mathrm{pH}$ bath where the $\mathrm{pH}$ was set 7 , the higher the alkalinity of the extraction bath, the greater was the $\mathrm{pH}$ drop rate. The drop rate became gradually slower while gradually approaching to more acidic bath from neutral bath. The $\mathrm{pH}$ was also measured after $24 \mathrm{~h}$ of the filtration process to notice

\begin{tabular}{|c|c|c|c|}
\hline \multirow[t]{2}{*}{ SI. No. } & \multirow{2}{*}{$\begin{array}{l}\text { Set } \mathrm{pH} \text { for } \\
\text { extraction }\end{array}$} & \multicolumn{2}{|c|}{ pH after extraction } \\
\hline & & After filtration & After $24 \mathrm{~h}$ of filtration \\
\hline 1 & 3 & 2.9 & 3.3 \\
\hline 2 & 4 & 3.9 & 4.2 \\
\hline 3 & 5 & 4.6 & 4.9 \\
\hline 4 & 6 & 4.9 & 5.1 \\
\hline 5 & 7 & 5.2 & 5.1 \\
\hline 6 & 8 & 5.9 & 5.6 \\
\hline 7 & 9 & 6.2 & 5.8 \\
\hline 8 & 10 & 6.4 & 6 \\
\hline 9 & 11 & 6.7 & 6.7 \\
\hline 10 & 12 & 7.3 & 7 \\
\hline
\end{tabular}

Table 3 Factors and levels in orthogonal design of experiment for aqueous extraction

\begin{tabular}{llll}
\hline Levels & Factors & & \\
\cline { 2 - 4 } & Temperature $\left({ }^{\circ} \mathrm{C}\right)$ & Time $(\mathrm{min})$ & Material-to-liquor ratio \\
\hline 1 & 80 & 45 & $1: 10$ \\
2 & 90 & 60 & $1: 13$ \\
3 & 98 & 75 & $1: 16$ \\
\hline
\end{tabular}

the stability of the extracted bath at acidic $\mathrm{pH}$, and no major noticeable change was reported.

Again, the dyes can show resonating form and give different tones with the change in $\mathrm{pH}$ because for natural dyes, $\mathrm{pH}$ changes very often. Furthermore, silk dyeing is recommended to be carried out in acidic medium as silk is sensitive to alkaline medium of dyeing, but extraction of the mangiferin dyes was optimized at alkaline $\mathrm{pH}$. Therefore, the stability of the dyes after extraction is of importance.

\section{Optimization of aqueous extraction conditions}

The levels for each of the three factors in the orthogonal design of experiments are shown in Table 3. The extraction experiments were performed under optimum $\mathrm{pH}$ condition $(\mathrm{pH}=10)$. The results of the orthogonal design of experiments are shown in Table 4.

Optimum factors: $\mathrm{A}_{3} \mathrm{~B}_{2} \mathrm{C}_{1}$,

Absorbance $=1.041$.

The optimum extraction conditions were $98{ }^{\circ} \mathrm{C}$ for temperature factor, $60 \mathrm{~min}$ for time factor, and 1:10 for material-to-liquor ratio. It has been found that dye liquor extracted under optimum conditions had the

Table 4 The absorbance values and range analysis from orthogonal experiment

\begin{tabular}{lllll}
\hline No. & A & B & C & Absorbance at $380 \mathrm{~nm}$ \\
\hline 1. & 1 & 1 & 1 & 0.802 \\
2 & 1 & 2 & 2 & 0.805 \\
3. & 1 & 3 & 3 & 0.779 \\
4. & 2 & 1 & 2 & 0.903 \\
5. & 2 & 2 & 3 & 0.859 \\
6. & 2 & 3 & 1 & 0.94 \\
7. & 3 & 1 & 3 & 0.856 \\
8. & 3 & 2 & 1 & 1.041 \\
9. & 3 & 3 & 2 & 0.999 \\
& A & B & $C$ & \\
$K_{1}$ & 0.795 & 0.849 & 0.988 & \\
$K_{2}$ & 0.910 & 0.917 & 0.906 & \\
$K_{3}$ & 0.981 & 0.903 & 0.789 \\
$R$ & 0.185 & 0.014 & 0.199 \\
\hline$K_{1}, K_{2}$, & $K_{3}-$ the average value of each factor when its level is 1, 2, or 3. $R$ - the \\
difference between the maximum and minimum results for each factor
\end{tabular}


Table 5 Shades of dyed silk

\begin{tabular}{|c|c|c|c|}
\hline Mordant & $\begin{array}{c}\text { No mordant (Reference } \\
\text { dyed) }\end{array}$ & Ferrous sulfate & Ferrous sulfate-alum \\
\hline \multirow{2}{*}{ Shade } & & & \\
\hline & New Wheat & Desert palm & Butternut \\
\hline Mordant & Ferrous sulfate-alum-tin & Alum & Alum + Tin \\
\hline \multirow[t]{2}{*}{ Shade } & & & \\
\hline & Curry & Tinsel & Cocoon \\
\hline Mordant & Tin & Tin + CT & Alum-Tin-TA \\
\hline \multirow[t]{2}{*}{ Shade } & & & \\
\hline & Straw & Bright gold & Honey mustard \\
\hline
\end{tabular}

maximum absorbance value, which was 1.041 . From the range analysis of the average absorbance results as shown in Table 4, the most influential factor of extraction was material-to-liquor ratio, while extraction time factor was the least influential.

\section{Dyed samples}

The use of mordants and their combinations produced different shades on silk fabric which are shown in Table 5.

\section{Color measurements of dyed fabrics}

The results of color measurements of the dyed silks are shown in Table 6.

$K / S$ value of the unmordanted dyed sample was found to be 11.85 . This dye uptake on the silk fiber is attributed to the structural features of the fiber. However, in the mordanting method, mordant resulted in improved color yield of the dyed fabrics, except tin. Ferrous sulfate as a mordant significantly increased the color yield of silk. The $K / S$ value was found to be 17.46 using ferrous sulfate which showed the maximum relative surface color strength value of $147.4 \%$ considering the unmordanted dyed sample as reference. Besides, using alum with ferrous sulfate, and tin and alum with ferrous sulfate as a combination, color strengths were found to be $140.3 \%(K / S=16.62)$ and $121.7 \%(K / S=14.42)$, respectively.

In single mordanting process of silk, the order of color yield was found to be ferrous sulfate $>$ alum $>$ tin. It was obvious that color yield gradually decreased when approached from ferrous sulfate to tin. Again, among the four different combinations of mordants, the order was

Table 6 Color yield, color coordinates, and color difference of dyed fabrics

\begin{tabular}{|c|c|c|c|c|c|c|c|c|}
\hline \multirow[t]{2}{*}{ Mordant type } & \multirow[t]{2}{*}{$K / S$ at $\lambda_{\max }$} & \multirow[t]{2}{*}{ Color strength (\%) } & \multicolumn{5}{|c|}{ Color coordinates } & \multirow[t]{2}{*}{$\Delta E_{C M C}$} \\
\hline & & & $\overline{L^{*}}$ & $a^{*}$ & $b^{*}$ & $C^{*}$ & $h^{0}$ & \\
\hline No mordant (Reference dyed) & 11.85 & 100 & 73 & 4.2 & 26.1 & 26.4 & 80.9 & - \\
\hline Ferrous sulfate & 17.46 & 147.4 & 30.6 & 3.3 & 8.1 & 8.7 & 67.8 & 19 \\
\hline Ferrous sulfate + Alum & 16.62 & 140.3 & 41.6 & 3 & 18.6 & 18.8 & 80.8 & 12.7 \\
\hline Ferrous sulfate + Alum + Tin & 14.42 & 121.7 & 61.1 & 4.7 & 22.2 & 22.7 & 77.7 & 5.1 \\
\hline Alum & 13.42 & 113.3 & 60.8 & 5.1 & 31.8 & 32.3 & 80.9 & 5.6 \\
\hline Alum + Tin & 13.13 & 110.8 & 74.7 & 3 & 27.2 & 27.4 & 83.7 & 1.6 \\
\hline Tin & 11.16 & 94.1 & 75.1 & 3.2 & 27.4 & 27.6 & 83.2 & 1.5 \\
\hline $\mathrm{Tin}+\mathrm{CT}$ & 13.19 & 111.3 & 65.3 & 5.6 & 32.1 & 32.6 & 80.1 & 4.4 \\
\hline Alum + Tin + TA & 14.62 & 123.4 & 62.8 & 5.8 & 30.96 & 31.51 & 79.34 & 4.78 \\
\hline
\end{tabular}




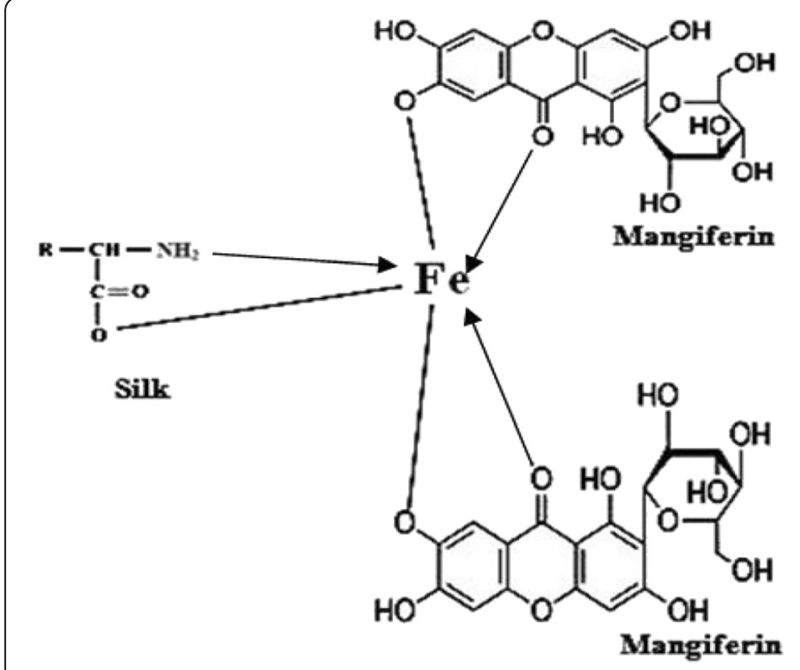

Fig. 4 Structure of mangiferin with ferrous sulfate on silk

found to be ferrous sulfate-alum $>$ alum-tin-tannic acid $>$ ferrous sulfate-alum-tin $>$ alum-tin.

The addition of ferrous sulfate mordant increased the greenness quality $21.58 \%$ when compared with the reference dyed sample. Tin reduced $22.23 \%$ redness while tin-CT increased $34.05 \%$ redness of the reference dyed sample. Again, from $b^{*}$ values, it was noticed that all the ferrous sulfate mordanted samples were bluer than the reference samples while tin-CT and alum-tin-TA mordanted samples increased yellowness of dyed fabric. The color saturation value $\left(C^{*}\right)$ were found to be least in ferrous sulfate mordanted sample (8.7) whereas the values were found to be maximum in the case of alum (32.3) and tin-CT (32.6) mordanted samples. Moreover, the hue angles lie within $67.8^{\circ}$ to $83.7^{\circ}$, so all of the dyed samples were closer to yellowish shade than the reddish. Higher color difference $\left(\Delta E_{\mathrm{CMC}}\right)$ was noticeable between reference and ferrous sulfate mordanted samples, and the difference reduced from ferrous sulfate to alum and then alum to tin as shown in Table 6.

The presence of hydroxyl or carbonyl groups in dye structure is capable to form metal complex with the positively charged metals. Dye anions and metal cations have strong attraction towards positively charged amino and negatively charged carboxyl groups of silk, respectively. Hence, they form ionic bonding between dye and fiber, metal and fiber, and finally dye and metal ions. The dye-metal complex also forms coordinate bonds with the uncharged amine $\left(-\mathrm{NH}_{2}\right)$ groups of silk as shown in Fig. 4. In addition, one molecule of dye can form a bond with one site of fiber molecule while one molecule of mordant can form bonds with two or more molecules of dyes. Therefore, these are some of the different features indicating application of mordants increased the color yield (Bhattacharya and Shah 2000; Temani et al. 2011; Uddin 2014).

Again, ferrous sulfate as a transition metal having coordination number 6 forms a large number of complexes with the dye molecules (Mongkholrattanasit and Punrattanasin 2012). As a result, when they interact with the silk fiber, some coordination sites remain free, and at that time, amino and carboxylic groups on the fiber can occupy these free sites. Thus, ferrous sulfate can form a ternary complex on one site with the fiber and in another site with the dye (Fig. 4). This strong coordination tendency can enhance interaction between the fiber and the dye (Bhattacharya and Shah 2000). This resulted in higher dye uptake as well as shade change due to mordanting with ferrous sulfate (Uddin 2014).

In contrast, aluminum and tin salts formed weak coordination complexes with the dyes. This tends to form quite strong bonds with the dye molecule but not with the fiber (Cotton and Wilkinson 1972). Thus, they block the dye and reduce its interaction with the fiber. This is the reason behind the lower $K / S$ values in the case of aluminum and tin salts than those obtained from

Table 7 Washing and light fastness of dyed fabrics

\begin{tabular}{|c|c|c|c|c|c|c|c|c|}
\hline \multirow[t]{3}{*}{ Mordant type } & \multicolumn{7}{|c|}{ Washing fastness } & \multirow[t]{3}{*}{ Light fastness } \\
\hline & \multirow[t]{2}{*}{ Color change } & \multicolumn{6}{|c|}{ Color staining } & \\
\hline & & Di-Acetate & Bleached cotton & Polyamide & Polyester & Acrylic & Wool & \\
\hline No mordant (Reference dyed) & 4 & $4 / 5$ & 5 & 5 & 5 & $4 / 5$ & 5 & 6 \\
\hline Ferrous sulfate & 4 & 5 & $4 / 5$ & 5 & 5 & 5 & 4 & 7 \\
\hline Ferrous sulfate + Alum & $3 / 4$ & 5 & $4 / 5$ & 5 & 5 & 5 & 4 & 7 \\
\hline Ferrous sulfate + Alum + Tin & 4 & 5 & 5 & 5 & 5 & 5 & 4 & 7 \\
\hline Alum & $4 / 5$ & $4 / 5$ & 5 & 5 & 5 & 5 & 5 & 6 \\
\hline Alum + Tin & $4 / 5$ & 5 & 5 & 5 & 5 & 5 & $4 / 5$ & 5 \\
\hline Tin & $4 / 5$ & 5 & 5 & $4 / 5$ & 5 & $4 / 5$ & 5 & 5 \\
\hline $\mathrm{Tin}+\mathrm{CT}$ & 5 & $4 / 5$ & 5 & $4 / 5$ & 5 & $4 / 5$ & 5 & 7 \\
\hline Alum + Tin + TA & 4 & $4 / 5$ & 5 & $4 / 5$ & 5 & $4 / 5$ & 5 & 6 \\
\hline
\end{tabular}


ferrous sulfate. Moreover, CT as an assistant increased the color yield from 11.16 to 13.19 when used with tin. $\mathrm{CT}$ is chemically potassium hydrogen tartrate which can be used in addition to dyes and mordants to change the $\mathrm{pH}$ in order to change colors and to help the absorption of the mordant metal (Mortazavi et al. 2012).

\section{Fastness results \\ Washing fastness}

The results of washing and light fastness of the dyed fabrics are shown in Table 7.

The unmordated dyed silk showed color change rating of 4 . This can be explained that the good fastness to washing for the sample dyed without mordant was due to the affinity of coloring component through $\mathrm{H}$-bonding and van der Waals forces. Using mordants, the color change ratings were found to be within $3 / 4$ to 5 , where a rating of 5 (excellent) was found using tin-CT mordant. The ratings were found to be $4 / 5$ in the case of using alum and alum-tin. So it can be said that the overall ratings of color change were good. As wash fastness is influenced by the rate of diffusion of dye molecules and state of dyes inside the fiber, dyes has a tendency to aggregate inside the fiber. Thus, their molecular size is increased resulting in good wash fastness. In addition, in the case of mordanted samples, complexing with mordant also has the effect of insolubilizing the dye, making it color fast.

On the other hand, the color staining ratings were found to be from $4 / 5$ to 5 for all the dyed fabrics, except when ferrous sulfate and its combinations were used as mordant. There were very slight staining observed on to the adjacent wool fiber of the multifiber fabric in the case of ferrous sulfate and its combination samples where the ratings were 4 and almost no staining on the other fibers of the multifiber fabric.

\section{Light fastness}

Light fastness as shown in Table 7 was found to be better, and among those, the lowest ratings attained were 5 in the case of tin and alum-tin combination while the unmordanted dyed fabric showed a rating of 6 .

In the case of metallic mordants, ferrous sulfate mordanted samples dyed with the mango leaf extracts showed excellent light fastness. This happened due to the formation of a complex with transition metal which protected the chromophore from photolytic degradation. The photons sorbed by the chromophoric group dissipated their energy by resonating within the six-member ring thus formed and, hence, protecting the dyes. Thus, ferrous sulfate can bind with more dye molecules than alum or tin. During exposure to light, the fabrics mordanted with ferrous sulfate, alum, or tin may have the same number of dye molecules destroyed.
But as the fabrics mordanted with ferrous sulfate had deeper shades due to bonding with more number of dye molecules, it seemed to fade less compared to the fabric mordanted with alum or tin.

\section{Conclusions}

This study was planned in search of greener alternative to satisfy the consumers' growing demand of eco-friendly products, and progress has been made with this study in the use of mango leaves extracts. The maximum relative color strength of the extracted dye liquor was found to be at $\mathrm{pH}$ 10. But the extracted dye liquors have shown good $\mathrm{pH}$ stability in acidic conditions. It was shown that different fashion hues were obtained on silk fabric from the same dye extract using mordants and their combinations. Again, color yields were found to be influenced by the addition of mordants. In single mordanting, the order of color yield was ferrous sulfate $>$ alum $>$ tin. In combined mordanting, the order was ferrous sulfate-alum $>$ alum-tin-tannic acid $>$ ferrous sulfate-alum-tin $>$ alum-tin. Other color values were also found to be influenced due to mordanting. Washing and light fastness properties were found to be from good to excellent in most of the cases. Thus, on the basis of the results, it can be said that mango leaves have good scope for application on silk fabrics.

\section{Competing interests}

The author declares that he has no competing interest.

Received: 6 April 2015 Accepted: 2 June 2015

Published online: 14 July 2015

\section{References}

Ali, S. (2007). Evaluation of cotton dyeing with aqueous extracts of natural dyes from indigenous plants (PhD Thesis) (pp. 62-63). Pakistan: University of Agriculture, Faisalabad. 96

Ali, MA, Almahy, HA, \& band Ali, AA. (2013). Extraction of carotenoids as natural dyes from the Daucus carota Linn (carrot) using ultrasound in Kingdom of Saudi Arabia. Research Journal of Chemical Sciences, 3(1), 63-66.

Ammayappan, L, Shakyawar, DB, Chhagan, L, Sharma, M, \& Wani, SA. (2014). Extraction of natural colourants from agricultural residues and their application on woolen fabric: part 2. Man Made Textiles In India, 57(6), 212-215.

Bains, S, Singh, OP, Goraya, G, \& Kang, M. (2003). Dyeing of cotton with mango (Mangifera indica) dye. Journal of the Textile Association, 64(1), 23-26.

Bhattacharya, SD, \& Shah, AK. (2000). Metal ion effect on dyeing of wool fabric with catechu. Color Technol, 116(1), 10-12.

Bruna, CV, \& Maria, AMM. (2013). Azo dyes: characterization and toxicity-a review. Textiles and Light Industrial Science and Technology, 2(2), 85-103.

Cai, Z, Jiang, G, \& Yang, S. (2001). Chemical finishing of silk fabric. Color Technol, $117,161$.

Clariant manual. Recommendations for dyeing silk. Sandoz Chemicals Ltd., Switzerland, ID 05543.00.94.

Cotton, FA, \& Wilkinson, G. (1972). Advanced inorganic chemistry: a comprehensive text (3rd ed.). New York: John Wiley \& Sons.

El-Nagar, K, Sanad, SH, Mohamed, AS, \& Ramadan, A. (2005). Mechanical properties and stability to light exposure for dyed Egyptian cotton fabric with natural and synthetic dyes. Polymer-plastics Technology and Engineering, 44(7), 1269-1279. doi:10.1080/03602550500207816.

Goodarzian, H, \& Ekrami, E. (2010). Extraction of dye from madder plant (Rubia tinctorium) and dyeing of wool. World Applied Sciences Journal, 9(4), 434-436. 
Hunger, K. (2003). Industrial dyes. Darmstadt: WILEY-VCH Verlag GmbH \& Co. KGaA.

Iqbal, J, Bhatti, IA, \& Adeel, S. (2008). Effect of UV radiation on dyeing of cotton fabric with extracts of henna leaves. Indian Journal of Fiber \& Textile Research, 33, 157-162.

Jothi, D. (2008). Extraction of natural dyes from African marigold flowers (Tagetes ereectal) for textile coloration. AUTEX Research Journal, 8(2), 49.

Khan, TA, Sharma, S, \& Ali, I. (2011). Adsorption of Rhodamine B dye from aqueous solution onto acid activated mango (Magnifera indica) leaf powder: equilibrium, kinetic and thermodynamic studies. Journal of Toxicology and Environmental Health Sciences, 3(10), 286-297.

Klaichoi, C, \& Padungtos, W. (2010). Development of batik painting technique silk fabric via natural dyes. In The 2nd RMUTP International Conference, Green Technology and Productivity (pp. 382-387).

Luo, F, Lv, Q, Zhao, Y, Hu, G, Huang, G, Zhang, J, et al. (2012). Quantification and purification of mangiferin from Chinese mango (Mangifera indica L.) cultivars and its protective effect on human umbilical vein endothelial cells under $\mathrm{H}_{2} \mathrm{O}_{2}$-induced stress. Int J Mol Sci, 13, 11260-11261. doi:10.3390/ ijms130911260.

Mahajan, S, Sidhu, SP, \& Grewal, J. (2005). Dyeing of silk with peach (Prunus persica) dye using combination of mordants. Journal of the Textile Association, 66(2), 85-89.

Mcdonald, R (Ed.). (1997). Color physics for industry (2nd ed.). Soc. Bradford: Dyers and Colorists.

Mongkholrattanasit, R, \& Punrattanasin, N. (2012). Properties of silk fabric dyed with eucaliptus, quercetin, rutin and tannin using padding techniques. Bangkok, Thailand: RMUTP International Conference on Textiles \& Fashion.

Mortazavi, SM, Kamali Moghaddam, M, Safi, S, \& Salehi, R. (2012). Saffron petals, a by-product for dyeing of wool fibers. Prog Color Colorants Coat, 5, 75-84.

Rawat, B, Jahan, S, Grover, E, \& Yadav, S. (2006). Color fastness properties of silk fabric dyed with poinsettia leaves. Asian Textile Journal, 15(4), 43-45.

Saravanan, P, Chandramohan, G, Mariajancyrani, J, \& Shanmugasundaram, P. (2013). A study on extraction and application of eco-friendly natural dye extracted from leaves of Acalypha indica Linn on silk fabric. International Journal of Textile and Fashion Technology, 3(5), 1-8.

Sivakumar, V, Jayapriya, J, Shriram, V, Srinandini, P, \& Swaminathan, G. (2009a). Ultrasound assisted enhancement in wattle bark (Acacia mollissima) vegetable tannin extraction for leather processing. J Am Leather Chem Assoc, 104(11), 375-383.

Sivakumar, V, Lakshmi, A, Vijayeeswaree, J, \& Swaminathan, G. (2009b). Ultrasound assisted enhancement in natural dye extraction from beetroot for industrial applications and natural dyeing of leather. UltrasonSonochem, 16(6), 782-789. doi:10.1016/j.ultsonch.2009.03.009.

Spyroudis, S. (2000). Hydroxyquinones: synthesis and reactivity. Molecules, 5, 1291-1330. doi:10.3390/51201291.

Suneeta, MB, \& Mahale, G. (2002). Dye from Parthenium leaves. Man-made Textiles in India, 45(5), 198-200.

Temani, P, Shakyawar, DB, Ammayappan, L, Goyal, V, \& Wani, SA. (2011). Standardization of dyeing condition of cochineal extract on pashmina yarn. Journal of the Textile Association, 72(2), 90-92.

Uddin, MG. (2014). Effects of different mordants on silk fabric dyed with onion outer skin extracts. Journal of Textiles, Article ID 405626, 1-8. doi:10.1155/2014/ 405626.

Win, ZM, \& Swe, MM. (2008). Purification of the natural dyestuff extracted from mango bark for the application on protein fibers. World Acad Sci Eng Technol, $22,536$.

\section{Submit your manuscript to a SpringerOpen ${ }^{\circ}$ journal and benefit from:}

- Convenient online submission

Rigorous peer review

- Immediate publication on acceptance

- Open access: articles freely available online

- High visibility within the field

- Retaining the copyright to your article

Submit your next manuscript at $\gg$ springeropen.com 